\title{
Mapping the human brain: comparing the US and EU Grand Challenges ${ }^{\dagger}$
}

\section{Dolores Modic ${ }^{1, *}$ and Maryann P. Feldman ${ }^{2}$}

${ }^{1}$ Faculty of Information Studies Novo Mesto, Novo Mesto, 8321, Slovenia and ${ }^{2}$ University of North Carolina at Chapel Hill, Chapel Hill, NC 27516, USA

*Corresponding author. Email: dollymod@gmail.com

${ }^{\dagger}$ The authors wish it to be known that in their opinion both authors should be regarded as joint First Authors. This work was begun when Dolores Modic was visiting UNC on a Fulbright Scholarship.

\begin{abstract}
The US Brain Research through Advancing Innovative Neurotechnologies Grand Challenge and the EU Human Brain Project Future and Emerging Technologies Flagship, though seemingly similar in many dimensions, have distinct features that have been shaped by politics and institutional systems. This article documents the history of the two projects and compares their organization and funding mechanisms. While there is a call for Grand Challenges to motivate science, organizational factors and the mechanisms for allocating funding will have a great influence on the ultimate project outcomes. These two divergent examples suggest alternative strategies to consider when organizing future Grand Challenges, and provide context that should be considered when evaluating the outcomes of large public investments in science.
\end{abstract}

Key words: neuroscience, Grand Challenges, science funding, EU Human Brain Project, BRAIN

\section{Introduction}

The European Union (EU) and the USA are simultaneously engaged in Grand Challenge research initiatives dedicated to mapping the human brain. The term Grand Challenge has captured the public imagination as a means to motivated large-scale scientific progress. The term gained popularity in 2003 when the Bill \& Melinda Gates Foundation identified fourteen Grand Challenges in global health (Singer et al. 2011). ${ }^{1}$ It is widely referenced that the concept originated in 1900 with David Hilbert's articulation of twenty-three important mathematical problems that set the agenda for mathematical research in the twentieth century (Omenn 2006: 1696; Grand Challenges Canada 2011: iv; JIIP 2012: 12; Gates 2013: A16). The discourse of Grand Challenges is now well established in policy making. ${ }^{2}$

Scientific research is a continually-ongoing endeavor. Grand Challenges-also sometimes referred to as 'global', especially by the The Organisation for Economic Co-operation and Development (OECD) or the UK Royal Society, or 'societal' (Kallerud et al 2013: 7) —articulate ambitious goals to harness scientific resources to solve important problems. In this case, the objective is to better understand and treat diseases ranging from autism to schizophrenia by mapping the human brain. The European Commission's (EC) Human Brain Project (HBP) was announced in January 2013. The US project, with the acronym, Brain Research through Advancing
Innovative Neurotechnologies (BRAIN), was announced in April 2013. Both Grand Challenge projects are characterized as 'visionary' and aim to be transformative with purpose-driven research that is both multidisciplinary and collaborative, relying on the integration of information technology and neuroscience. Both Grand Challenges support basic research; however, generating new technologies and (eventually) increasing competitive economic advantage are prominently mentioned as intended outcomes. These characteristics distinguish them from mission-oriented R\&D projects—such as Apollo or the Manhattan Project-and represent new challenges for science (Foray et al. 2012: 1698). Moreover, despite having a similar research focus, the two Grand Challenges differ in significant ways, reflecting institutional context and political negotiations.

The two Brain Grand Challenge initiatives may be viewed as experiments in the organization and allocation of resources for ambitious, high-risk scientific projects. The two projects offer contrasting organization-with the EU project highly centralized, while the US project is highly decentralized. For far too long the emphasis has been on the scale of funding. While, of course, more money is always preferred to less, it is the organizational design factors that determine how money is allocated, and to whom. Thus, the design of the Grand Challenge project-which includes the determination of eligible participants, the incentives, and the parameters that influence the pace of progress-may be even more important than the 
scale of funding. The institutional origins of science policy initiatives are, inter alia, of utmost importance in evaluating their success (Link 2014). We argue that, in addition, the design and implementation of the Grand Challenges will determine their ability to ultimately achieve their objectives.

Our purpose is to document and highlight the above mentioned differences between these two projects for any future evaluations, and to offer insights that may be useful to the design of future Grand Challenges. The next section discusses the history of the evolution of the idea of mapping the human brain. While the idea of understanding the human brain has been aspirational for a very long time, recent technological advances have helped bring us within reach of achieving this objective. Although the development and adoption of new, more effective, technologies is a necessary condition, it is not a sufficient one for achieving the aims of Grand Challenges (Foray et al. 2012: 1697). Following this, we consider how each of the two initiatives entered public discourse and received the Grand Challenge designation. We then describe and delineate the institutional frameworks of both the HBP and the BRAIN. This provides us with the opportunity to draw comparisons of these two Brain Grand Challenge initiatives in terms of: their embeddedness in institutional setups, the participating entities, organization of the projects, budgetary constraints, and project criticisms. Familiarity with different, already existing, Grand Challenges can provide useful insights not only for their evaluation, but also to offer guidance for the development of new Grand Challenge initiatives. The article ends with contemplation on possible future evaluation challenges.

\section{Evolution of the idea of mapping the human brain}

Schizophrenia, depression, epilepsy, dementia, alcohol dependence and other mental, neurological, and substance use (MNS) disorders constitute 13 per cent of the global burden of disease, surpassing both cardiovascular disease and cancer (Collins et al. 2011). Table 1 provides disability-adjusted life years $\left(\mathrm{DALY}^{3}\right)$ for specific MNS disorders. These disorders also constitute a major financial burden; yearly costs of brain diseases are estimated at $€ 800$ billion in the EU (DiLuca and Olesen 2014). In the USA, the cost of caring for people with Alzheimer's disease alone is over $\$ 200$ billion per year (Strategy for American Innovation 2015). Across all countries, investment in fundamental research into disorders affecting the brain is disproportionately low relative to the disease burden (Saxena et al. 2007).

Scientific understanding of the brain has proven elusive, despite significant advances in the understanding and treatment of diseases affecting other organ systems. The idea of mapping the human brain has a long history dating at least as far back as the seventeenth century (Zimmer 2004; Wade 2010). Starting in the mid-nineteenth century it became scientifically fashionable to map the functions of the brain using a variety of methods and techniques. Advances in neuroscience-a relatively young scientific field that emerged in the mid-twentieth century-have generated a scientific basis to begin achieving an understanding of the brain's structure and functions (Pechura and Martin 1991). Neuroscience is an emerging scholarly field that is concerned with the scientific study of the brain and central nervous system (Finger 1994 provides a historical account of the development of the field.). It has been a splintered field with a variety of different approaches and orientations seeking to dominate the field (Koch and Reid 2012: 397). Advances in less invasive imaging
Table 1. Global burden of MNS disorders, DALYs ${ }^{\mathrm{a}}$ (millions)

\begin{tabular}{llc}
\hline Rank & Cause & DALYs (in millions) \\
\hline 1 & Unipolar depressive disorders & 65.5 \\
2 & Alcohol use disorders & 23.7 \\
3 & Schizophrenia & 16.8 \\
4 & Bipolar affective disorder & 14.4 \\
5 & Alzheimer's and other dementias & 11.2 \\
6 & Drug use disorders & 8.4 \\
7 & Epilepsy & 7.9 \\
8 & Migraine & 7.8 \\
9 & Panic disorder & 7 \\
10 & Obsessive-compulsive disorder & 5.1 \\
11 & Insomnia (primary) & 3.6 \\
12 & Post-traumatic stress disorder & 3.5 \\
13 & Parkinson's disease & 1.7 \\
14 & Multiple sclerosis & 1.5 \\
\hline
\end{tabular}

Data from WHO (2008). Examples of MNS disorders under the purview of the Grand Challenges in Global Mental Health initiative.

${ }^{\mathrm{a}} \mathrm{A}$ DALY is a unit for measuring the amount of health lost because of a disease or injury. It is calculated as the present value of the future years of disability-free life that is lost as a result of the premature deaths or disability occurring in a particular year.

technologies—such as functional magnetic resonance imaging-have helped provide a greater understanding of neurons, circuits, and brain systems (Kandel and Squire 2000).

US President Bush declared the 1990s as the Decade of the Brain. This declaration was not accompanied by a significant funding commitment to brain science, however, the simple act of a Presidential Declaration was beneficial as it brought visibility to the field of neuroscience (Jones and Mendell 1999). Interest in the brain also caught public attention with actions such as the month of May being proclaimed by the EC as 'European Month of the Brain', or the Brain Awareness Week (supported by the Society for Neuroscience), which has attracted support from thousands of organizations across the globe (Castillo 2015). The idea for the latter originally started in 1993 by the Dana Alliance for Brain Initiatives-an initiative of the Dana Foundation, a private philanthropic organization established in 1950 and dedicated to advancing brain research. In 1994, a document titled Grand Challenges in Medical Informatics by Dean F. Sittig, an expert in Biomedical Informatics, included the objective of 'a complete threedimensional, digital representation of the body, including the brain'. Sitting's ideas, which were highly cited in other relevant documents and publications, helped popularize the concept of brain mapping.

Inspired by the success of the Human Genome Project (HGP), the parallel idea of mapping the human brain began gaining scientific and political traction in the early 2000s (Fitzpatrick 2016). The parallels in using the term 'mapping' in the naming of the projects is obvious, as is the idea of understanding these fundamental structures. Along with these parallels, however, there are some important distinctions. The HGP was an international, collaborative research project formally launched in 1990 with the objective of a complete mapping of all the genes of human beings (Cook Deegan 1994). A similar and competing project was conducted outside of government by the Celera Genomics. The latter was formally launched in 1998, creating a scientific race (Shreeve 2004) with the Human Genome that was declared complete in 2003.

Horgan (2013) warns for caution in comparisons of the Brain Mapping Grand Challenges to the HGP. Horgan (2013) points out 
that the Genome Project was built upon a basic understanding of genetics that dated back decades to when researchers first deciphered the genetic code and defined sets of rules whereby specific sequences of base pairs in DNA generate specific proteins. Progress in neuroscience has been more fragmented. The prevailing understanding is that the brain operates according to a neural code. This notion relies on functional scans of activities in brain regions, and smaller scale expression of neurotransmitters and their receptors in individual neurons. The connection between these two scales is conceptualized as a map of the human neural network, or human brain that draws heavily on the integration of computer and information science.

Philanthropic foundations played a catalyzing role in defining the field of brain mapping. A culminating event was the 2011 Allen/ Gatsby/Kavli Workshop that produced a proposal for a large-scale public initiative, called the Brain Activity Map (BAM) project (Alivisatos et al. 2012). When this initiative was formally announced, many public and private organizations were already championing or funding projects in the field. Philanthropist Paul Allen started an initiative with the goals of understanding how the human brain works, and changing the way that researchers approach brain disease and disorder in 2000. In 2003, the Allen Institute for Brain Science began mapping regions of gene activity in the mouse brain and pooling results into online databases, or atlases (Koch and Reid 2012). The open provision of comprehensive maps of brain activity facilitated further research. The UK Gatsby Charitable Foundation, funded in 1967 by David Sainsbury, began investing in neuroscience in 1990. Their goal, 'Supporting worldclass theoretical and experimental research on neural circuits and behaviour, and activities', aligns with the current direction in the field. The Kavli Foundation (2000) has championed the Brain project through organizing symposia, as well as bringing together different researchers at their Kavli Institute, which have published papers on the brain mapping initiative. The 2012 drafted paper in Neuron has authors who are mostly (all but two) connected to the Kavli Foundation (the most visible author, George Church, being one of the people who helped initiate the HGP initiative). The relative speed of the process itself can thus be attributed to an already existent cohort of combined efforts in this area.

On the eve of the Grand Challenge announcements, a 2014 Elsevier report, Brain Science: Mapping the Landscape of Brain and Neuroscience Research, found that 1.79 million brain and neuroscience research articles were published between 2009 and 2013. This represented one-sixth of the world's total publication output (Elsevier 2014: 3). Still, Holzinger (2014: 35) claims that although much progress has been made, many of the points articulated in Sittig's 1994 goals are still unrealized after 20 years.

\section{Getting on the public agenda}

Grand Challenges require that heterogeneous elements and forces have to be mobilized, guided, and integrated; taking into account that perspectives on the problem at hand, and what constitutes its resolution, can differ significantly across various groups (Kuhlmann and Rip 2014). The process of defining the objectives of the Grand Challenge, garnering support from various constituencies, and reaching consensus, is achieved through agenda setting. While individuals or private foundations engage in an internal process, the public definition of a Grand Challenge is more transparent and based on this initial agenda-setting process. The two Grand Challenges differ significantly in the ways they emerged on their respective political agendas (Fig. 1), although both ultimately led to what could be called initiatives driven by institutional pillars of science policy-actors who are consummate insiders and agenda setters (Hicks 2016).

In Europe, several groups have produced influential documents; some aimed at defining and formulating the Grand Challenge approach and others working to point toward specific Grand Challenges. The 2008 report Challenging European Research: Rationales for the European Research Area, by the ERA Expert Group, emphasized the need to engage the European research system in Grand Challenges and the need for corresponding investments. In 2009, the so-called Lund Declaration emphasized that Europe must focus on the Grand Challenges of our time by connecting science organizations, politicians, and industry representatives. Both reports could be seen as key EU documents furthering the Grand Challenge discourse in Europe (see also Wissenshaftsrat 2015: 9, 10). Other important documents include: The Role of Community Research Policy in the Knowledge-based Economy (2009); Strengthening the Role of European Technology Platforms in Addressing Europe's Grand Societal Challenges (2009), ICT-FP7 Work Programme 2011-2012 (2011).

In regard to establishing brain research as one of the fields inside the Grand Challenges approach some documents also need to be pointed out. Two Information and Communications Technology (ICT) Advisory Board's (ISTAG) reports from 2009 (a year prior to the initial call for EU Grand Challenge Flagship Pilots) are of particular interest: ISTAG Recommendations on Future and Emerging Technologies and ISTAG Report on European Challenges and Flagships 2020 and beyond. The first report identifies the recording and imaging of the brain as one of the long-term challenges in ICT (ISTAG 2009a: 32). The second report sees 'a breakthrough ... "Understanding life ... no longer science fiction but ... becoming a feasible challenge thanks to the advances in biological sciences and in ICT" (ISTAG 2009b: 17) and list as possible directions of the research inter alia in Simulating Life Challenge, Emulating Life Challenge, and Neuro-ICT Challenge (ISTAG 2009b: 18, 19). Interestingly, Henry Markram, who later became head of the HBP, was a member of the ISTAG at the time these reports were published. Furthermore, in the Joint Institute for Innovation Policy's Study to Assist the European Research Area Board: Investing in Research and Innovation for Grand Challenges (2012) healthy ageing appears among two listed examples of Grand Challenges in the last document, where various ICT-related research and imaging are discussed (JIIP 2012: 24). Furthermore, human brain research was already present in the EU's 2010 Future and Emerging Technologies (FET) Flagship call for proposals, and in the European Forward Looking Activities Report that emphasized the need for 'better knowledge of human brain' (European Commission 2011: 5).

Hence, the EU's scientific and political rhetoric of Grand Challenges is well established, and is also apparently here to stay: the EU has in May 2016 announced the new Quantum Technologies Grand Challenge; launching another $€ 1$ billion worth flagship. The study of the brain has also already gained its place inside the Grand Challenges and was crystallized as such through various official channels, previous funding schemes, and competitions. In the EU, more than $€ 2$ billion were dedicated to brain research starting in 2007; additionally, brain science has become a part of the mainstream EU research agenda (DiLuca and Olesen 2014: 1208). Brain research and combating major diseases related to brain health was one of the European major fields of community action within the Seventh Framework Programme for Research and Technological 
Development (FP7)—EU's main instrument for funding research between 2007 and 2013. With that said, combating major brain diseases was not included in the FP7 until the very last moment, following pressure generated by newly-published brain science research results (Olesen et al. 2006; Sobocki et al. 2006). However, the research area had never achieved such (political and research) traction as it has today through this single project.

The HBP was conceived at the interface of neuroscience and information technology, similar to its direct predecessor, the Blue Brain Project, which had the same leading institution, and partners. ${ }^{4}$ Henry Markram is strongly identified with the HBP, providing an example of science policy advocacy (Dickson 1988). We concur that maneuvering by the scientific community is a surprise only to those who believe the scientists' plea is above politics (Dickson 1988). It is often claimed that HBP was sold by the charismatic Henry Markram with his politically-expedient rhetoric.

The selection of the HBP-as a so-called FET Flagship-was a formal, multiyear, top-down multistep procedure, with (anonymous) peer-to-peer reviews. This formal selection process should increase transparency, decrease subjectivity, and in abstractu increase the autonomy of the scientific community. However, while scientists usually do a good job in evaluating scientific merit, they tend to have more problems in evaluating the utility of the projects. Opponents have also criticized the selection process as secretive; although the European Commission (2014: 24) insists that the selection process was competitive and driven by scientific excellence. Interestingly, the other selected FET Flagship-the Graphene Project-was never submitted to such detailed scrutiny. Nonetheless, the fact remains that the peer-to-peer selection processes are seen as increasingly problematic (Irvine and Martin 1985) in a world where Grand Challenge projects demand increasing funding and where there is a high concentration of research activity inside individual big research consortia.

President Obama's State of the Union address in February 2013, days after the EU announced the HBP, mentioned the new BRAIN project as built upon the 2011 BAM (Insel et al. 2013; Yuste and Church 2014). The designation of BRAIN Grand Challenge relied on the President's initiative, with the support of the Office of Science and Technology Policy (OSTP). OSTP was uplifted by the fact that plenty of efforts already existed in this field. Another distinctive feature of BRAIN is its reliance on informal interactions, as has often been the case in the past (Brooks 1978; Cook Deegan 1994). The descriptions of formal decision-making processes can only be seen as an approximation, due to the importance of informal interactions (Brooks 1978; Dickson 1988).

Hicks (2016) traces the emergence of the Grand Challenges in the US science policy to Kenneth G. Wilson, who emphasized the importance of leveraging supercomputers (in basic science)-an issue strongly ingrained in the current brain initiatives-back in the 1980s. This made high performance computing the field in which the idea of Grand Challenges first permeated science policy-as evidenced by the High Performance Computing and Communication program in the 1980s, and the regulatory framework with the High Performance Computing Act of 1991 (Hicks 2016).

The first mention of the Grand Challenge from a federal agency in the field of brain research was in the Report on Grand Challenges of Mind and Brain-drafted after workshops were held at the National Science Foundation (NSF) in 2006-that described emerging issues and new directions for research in neuroscience and cognition. Several elements were seen as critical to the success of the initiative, including multidisciplinarity and the importance of broad questions that could be solved by many small-scale partnerships rather than by few large-scale clusters. Some other documents on Grand Challenges that are loosely connected to the brain research field include: Grand Challenges for Biological and Environmental Research: A Long Term Vision from the Department of Energy (DOE) (2010) and Grand Challenges: Science, Engineering, and Societal Advances Requiring Networking and Information Technology Research and Development (2006) by the Interagency Working Group on Information Technology Research and Technology; and A New Biology for the 21st Century of the National Research Council (2009)—-the latter also points out that society at large could benefit from large-scale efforts to understand how the brain works. Brain research, or even the more general topic of neuroscience, was not listed among examples of possible Grand Challenges by the President; neither in the original President's Strategy for American Innovation from November 2009, nor in the revised Strategy from 2011. However, brain research has been prominently mentioned in the Strategy revision of $2015 .^{5}$

Furthermore, there is evidence that an informal advocacy process operated, with bipartisan congressional support and active bipartisan congressional actors, for example, the bipartisan Congressional Neuroscience Caucus that was established in 2010. The purpose of the Caucus is threefold: to build awareness of brain research, to help communicate the progress and benefits of brain research, and to inform policy makers. A particularly strong advocate was also Congressman Chaka Fattah, who launched his Fattah Neuroscience Initiative back in 2011. Neuroscience continued to gain momentum within federal agencies, as evidenced by the many government reports written on the various scientific challenges in the field. Though momentum started building in the 2000s, brain science gained even more political traction in the USA sometime after 2011. Around this time, with the increased activity around brain science research, there was encouragement from Congress to consolidate neuroscience projects. Thus, the Interagency Working Group on Neuroscience (IWGN) was established in 2012 (and re-established in 2015 after releasing its final report in 2014), with participation from over twenty agencies and departments, including the NSF, the DOE, etc. The IWGN is part of the wider White House Neuroscience Initiative that promotes partnerships with the private sector to advance neuroscience research.

\section{Grand challenge institutional frameworks}

Grand Challenges rely on institutional frameworks as they work to solve scientific problems. Their institutional frameworks enable them to determine: who participates, how resources are allocated, and how the inevitable disputes should be addressed and resolved. These institutional frameworks provide the rules, or guidelines, that projects must adhere to during the Challenge.

Both Grand Challenges declare the potential commercial value of research results and emphasize their potential to create new industries and jobs for the future. While the Grand Challenges acknowledge their potential to impact economic development, they are both-first and foremost-science projects. There has long been emphasis on 'some sort of direct transfer from science as a mode of knowledge to technology as a mode of know-how for making useful things and performing useful activities' (de Sola Price 1984); this would be a strong argument for inclusion of more companies from early on to expedite this possible trickle-down effect of Grand Challenge initiatives. However, as we will see, the current approach 
of both projects has been somewhat different in terms of inclusion stakeholders. There is, however, a joint vision in the EU and in the USA that-following technology development-both brain initiatives should offer an infrastructure for sharing relevant tools. ${ }^{6}$

EU research programs are required to satisfy legal and political obligations dictated by the Amsterdam Treaty and resource allocation decisions made by the EU follow a prescribed selection process. However, the EU is not necessarily the most logical administrative decision-making unit because of distinct national research policies in addition to limited supranational integration.

As a designated part of EU FET Flagship initiative (Fig. 2), the HBP's main objective is to simulate the functioning of the human brain with a supercomputer. This objective re-enforces the idea that this Grand Challenge is an ICT initiative.

The EU is committing $€ 1$ billion in the next 10 years to this single and centralized project. Half of that amount was provided by the EC, and the other half mainly by Member States. FLAG-ERA, the Flagship European Research Area Network, was established in 2013 to gather national and regional funding to support the flagships (as well as nonselected flagship pilots ${ }^{7}$ ) inside the so-called partnering part, providing further funding opportunities for other interested (research or business) partners. However, funding organizations from only eleven countries (out of twenty-eight EU Member States, plus Turkey) were participating in the 2015 Joint Transnational Call (JTC) that supported the HBP; furthermore, only ten countries participated in the 2016 JTC, supporting the four nonselected FET Flagship Pilots. ${ }^{8}$ Most notably absent from both calls was Germany. Hence, this vertical splitting of funding with expected major contributions by the EU Member States is cause for concern, especially given that only a few of them have made serious commitments (the same can be said for planned private contributions). The initial funding for HBP comes from the FP7 schemes. It was not until the signature of the Framework Partnership Agreement in October 2015, while the project was entering the end of the FET Flagship's 'Ramp-Up Phase', that HBP was officially financially made part of the FET Flagship. However, this initial funding, related to FP7, does not increase the flexibility of the funding, since the budgetary framework was pre-planned.

Coordination of the HBP is centralized with the leading partner École Polytechnique Fédérale de Lausanne (EPFL) based in Switzerland. Barriers in achieving European leadership in this area are seen in fragmentation and under-investment, which could explain why the project was designed to be centralized and receptive of a large influx of funding. Another interesting political note is that the EU is willing to fund a major project that is coordinated by an organization that has its headquarters outside the EU borders. However, all organizations based in the European Economic Area are eligible to receive funding from EU, due to the Agreement on the European economic area.

HBP emphasizes scientific excellence in terms of involved actors, with only three companies listed among partners. In general terms, the flagships aim to deliver world-beating science at the crossroads of science and technology (European Commission 2013). In a way, this is contradictory to the ideas emerging inside the EU and emphasized inside Horizon 2020, whereby a more utilitarian view of science has been adapted. Hence, the project seems to be set up to contribute to the European paradox in the field of brain science; the EU scientific performance being 'excellent' compared to its biggest competitors (e.g. the USA), while Europe's major weakness lies in the difficulty of transforming the results of the research into innovations and, ultimately, competitive advantages. However, some argue it is not only the formal institutional framework that provides a barrier, but also the lack of European companies that would be able to step in to those sectors with the greatest opportunities for innovation-based growth (Veugelers and Cincera 2015). The OECD data on the revealed technological advantage (RTA), based on patent data, seems to indicate a similar story; demonstrating that there does not seem to be any technological advantage in the biotechnology field in Europe (although some individual countries differ from this general picture), whereas the USA does appear to have a technological advantage in this field (OECD 2015: 196). This deficiency allows multinational and US firms to benefit from major European advances (Dosi et al. 2005: 32). Also the process of defining the Grand Challenges is itself mostly confined to so-called scientific elites; although a strong emphasis is in abstractu on uniting 'all relevant forces across Europe in working towards solutions for societal challenges' (e.g. Strengthening the Role of European Technology Platforms in Addressing Europe's Grand Societal Challenges 2009: 8).

HBP has often been criticized; this culminated in the Open Letter (2014) signed initially by more than 100 individuals (who were eligible for HBP funding) and an evaluation-formally, a mediation process-in 2015. The project was criticized inter alia for lack of transparent administration, with the evaluation highlighting the need for a more efficient organizational structure. In a situation where projections showed more funding would be required, a high degree of administrative centralization presents a possible barrier to realizing scientific progress.

The US approach, called an 'all hands on deck' approach by President Obama, is decentralized, involving multiple federal mission agencies, private philanthropic foundations, and for-profit firms (Fig. 3). Among industrial partners, the US Photonic Industry, GlaxoSmithKline, Google, General Electric, and some others are mentioned inside the BRAIN Grand Challenge. However, this approach does not only encompass the implementation level of individual Grand Challenges, but also their conceptual level; some firms have defined additional Grand Challenges that have the potential for wide societal benefits (e.g. SpaceX's 'making humanity a multiplanetary species', or Google's self-driving cars); see also Strategy for American Innovation 2015. The BRAIN Grand Challenge is accompanied by three other so-called Presidents 21st Century Grand Challenges, which are implemented by different government agencies that have identified 'North Stars' in US research endeavors (e.g. NASA implementing the Asteroid Grand Challenge). Despite these additional Grand Challenges, the BRAIN appears to be the 'poster-child' for them, partially because it has garnered the most diverse agency support.

The number of federal agencies participating in the BRAIN initiative is continuously increasing. Currently involved are: the National Institutes of Health (NIH), the Defense Advanced Research Projects Agency (DARPA), the NSF, the Intelligence Advanced Research Projects Activity (IARPA), the Food and Drug Administration (FDA), and - the latest participant-the DOE. This range of participating federal agencies provides diversity to the developing research portfolio, but also presents coordination challenges, with the possibility to 'devolve into a wish list' (Yuste and Church 2014).

The criticism of the BRAIN thus far has been much more reserved than the criticism of the HBP. Most criticism is confined to individual criticisms (see e.g. Fields 2013; Horgan 2013), often related also to the fact the BRAIN is more a bundle of projects in the same field, rather than a single Grand Challenge project. The Advisory Committee of the Brain Working Group's (NIH ACD) 


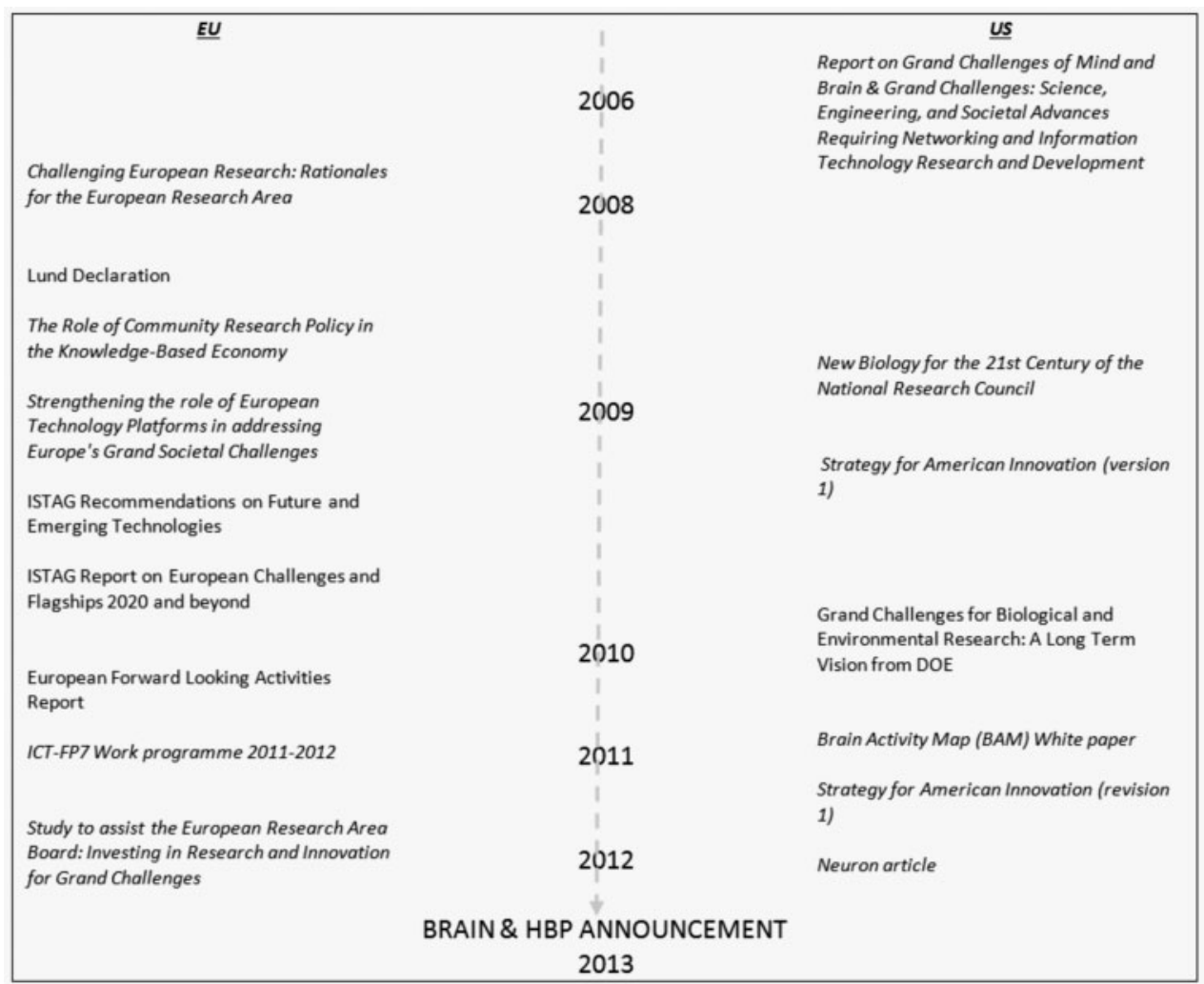

Figure 1. Important documents defining the Grand Challenge approach and the role of brain research therein, for EU and the USA from 2006 to 2013. Notes: We agree with Kallerud et al. (2013: 4) that 'as the number and variety of uses and developments of the Grand Challenges rapidly increases, it becomes impossible to make an exhaustive map of these developments'. Hence, the need to make choices about which documents to highlight as important or exemplary is inevitable. Please keep in mind also that our narrower focus to Brain Grand Challenges dictated the authors' selection.

document BRAIN 2025 provides a vision for this project. The document identifies seven goals, which appear to be in line with the previous plan 'to significantly extend and shape the vision' of the BAM (Insel et al. 2013). Although the document provides a scientific plan-including timetables, milestones, and cost estimates-for achieving project goals, different involved agencies strive to achieve different individual goals and the abovementioned document primarily represents the perspective of the NIH. Hence, this decentralization of efforts may present future problems when evaluating the overall results of the BRAIN.

The BRAIN project was seeded with approximately $\$ 100$ million from public funds, with private partners committing more than $\$ 100$ million annually. ${ }^{9}$ The project has two distinct features: a horizontal decentralization of funding organizations and financial commitments from both the public and private sectors. The President's budget increased federal funding to more than $\$ 300$ million in 2016; and, in March 2016, the commitment for financial year 2017 has more than quadrupled from the initial $\$ 100$ million per year (The White House 2016). General funding trends also play a role. The US Congress tends to increase funding for biomedical research; hence, the White House requested lower funding while anticipating, and relying on, this increase (Dickson 1988). The BRAIN is an excellent example of this; NIH will get $\$ 25$ million more than requested in 2016 in order to support this challenge. Many different ideas exist on how NIH funds should be allocated (Sampat 2012). The BRAIN challenge follows a viewpoint, identified with many prominent researchers, that NIH should fund research that is, in its nature, basic research. However, the designation of a Grand
Challenge implies that a more practical output is expected, shifting the image and discourse of the research to be done toward health instead of science, since it was argued that this is what gets a lot more traction with the Congress and the public (Kaiser et al. 2010). Year to year budgeting provides elasticity, and increasing funds are bound to have positive effects.

\section{Conclusions}

Calls for accountability in the use of public funds require greater attention to institutional context and organizational structure, as these ultimately determine the evaluation of a project's success. As it was pointed out by Flyvberg et al. (2003: 73), projects do not exist in the simple 'Newtonian world of cause and effect, but rather in a reality where the implementation is highly stochastic'. Thus, Grand Challenge projects-often riddled with fundamental uncertaintiesrarely end up as originally planned in terms of involved actors, budgetary commitments, and results. Any subsequent evaluation efforts face not only a complicated societal reality-with a plethora of desired objectives for the Grand Challenge projects—but also must overcome the fact that Grand Challenge projects are complex on their own. There are several factors that contribute to the challenging task of evaluation. Science and technology interact with society in a complex way, as their effects are often neither immediate nor direct, but often occur indirectly and after a substantial time delay. There is uncertainty about tomorrow's developments, including the fast pace of (sometimes) competing technological changes and solutions. Grand 


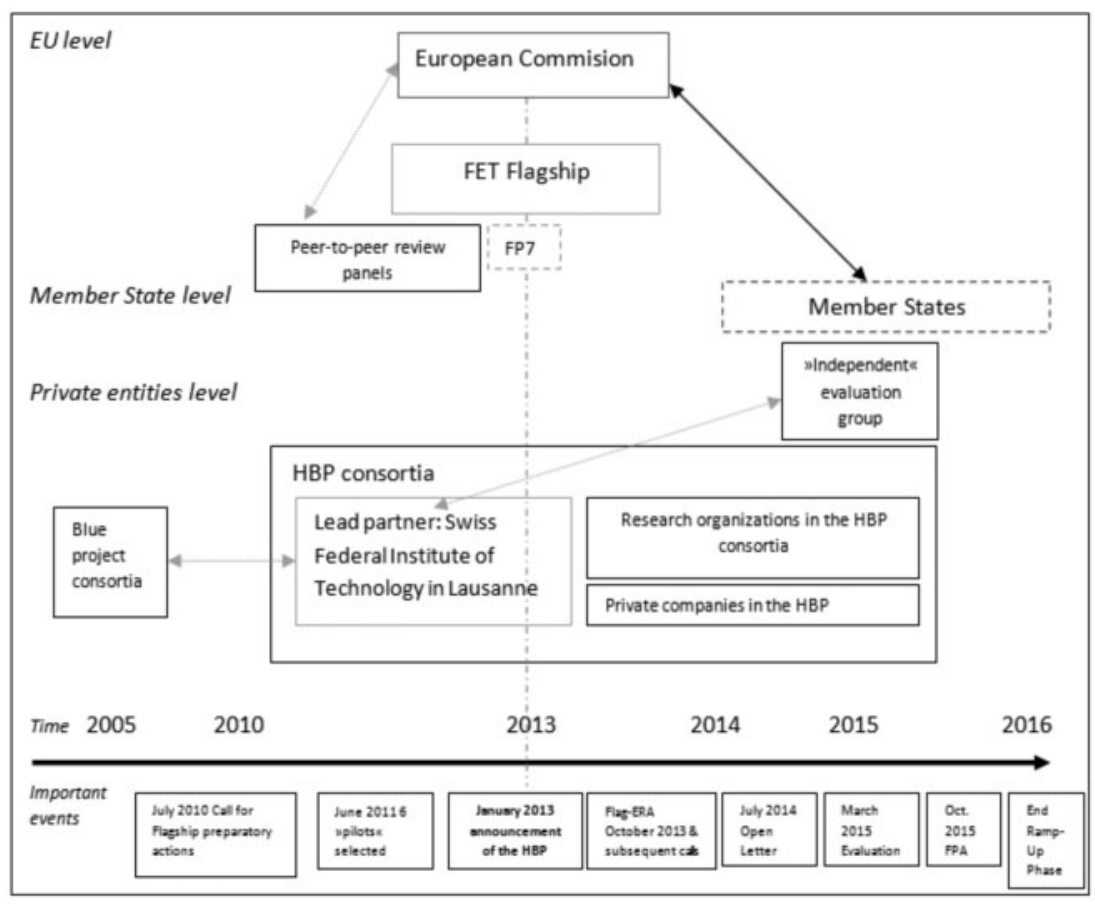

Figure 2. EU HBP science policy landscape.

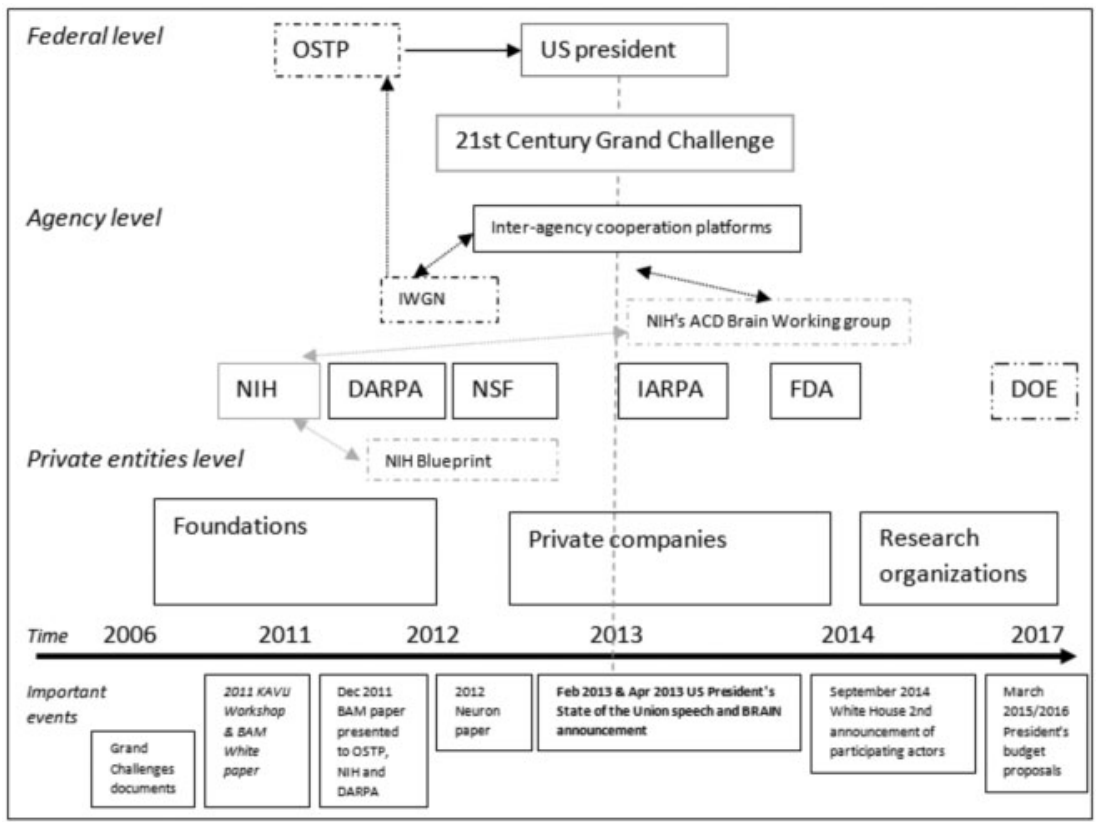

Figure 3. US BRAIN science policy landscape.

Challenge projects often rely on the populist rhetoric of the projects, where the real potential—and, subsequently, the goal-is sometimes less clear, making comparisons with the base-line difficult. This goes hand in hand with difficult evidence gathering (Levidow and Papaioannou 2016) in light of the fact that the ultimate output (national health) is a quintessentially public good (see mutatis $m u$ tandis for defense-related projects in Mowery 2012: 1709). Increased budgetary demands of the projects are accompanied with lock-in effects, where existing projects call for either increased funding or, at least, a steady income of funds-based on the idea that a significant amount of funding has already been locked into a certain endeavor. There is also a plethora of involved actors, and their interactions are sometimes difficult to assess. The evaluation will hence need to combine: diagnoses of the (presumed and current) problem(s); the analysis of (non)impacted societal visions; interposing policy narratives; objective cost-benefit analysis (including spin-outs positive effects); and diligent evidence gathering. 
In order to effectively capture the effects of both initiatives, multiple evaluation methods will need to be considered. The authors suggest inter alia to employ a burst data mining-based technique called DETECTS, originally developed by Kleinberg (2003) and recently applied to patent and publication data by Dernis et al. (2015). Patentand publication-based bursting allows detecting the emergence of technologies as well as the evolution and co-development trajectories that occur in science (and technology). A patent-based bursting evaluation would show if relevant patent (International Patent Classification) fields connected to brain mapping inside published patent documents show any significant signs of bursting; that is, whether there is significant increase in those applications. This indicates not only new emerging technologies in the field (spin-off effects), but also whether the brain initiatives have truly generated the promised 'excitement' inside the research community, both in the academia and the industry.

As demonstrated above, we were able to identify several differences between the projects. Some- including Sean Hill, the co-director of the HBP's neuroinformatics team, and Rafael Yuste, one of the authors of the BAM paper-believe the US and EU initiatives have complementary missions. The BRAIN aims to create tools for imaging and controlling brain activity, while the HBP seeks to create a working computational model of the entire brain. As so eloquently put by Reardon (2014), 'just as the HBP needs actual brain data to design its model, the BRAIN Initiative needs a system for integrating its massive amounts of biological data so that it can generate something meaningful'. Hence, instead of having another 'space race' on our hands, the emphasis inside the scientific community should be on the possibilities of international collaboration.

However, on the political level, competition seems to be a prevailing discourse inside the brain projects' rhetoric. Not only do distinctions in national objectives cause variations in Grand Challenge policies, but also diverse industrial and political environments influence the design and operation of both presented brain initiatives. ${ }^{10}$

In an era of brain science where the potential for scientific advance is within reach and the societal need is great, how these projects will fare and their ultimate outcomes will only be revealed with the passage of time (and rigorous evaluation). Kalil (2012) writes that 'support for curiosity-driven research is critical, both because expanding the frontiers of human knowledge is an end in itself, and because it leads to benefits that we could never have predicted'. Both projects are pouring large amounts of money into neuroscience and the related fields, encompassing and activating numerous scientists and organizations; hence, we are bound to achieve various beneficial spin-outs. But more than the dollar amount of funding, it is clear that the organization and implementation of these Grand Challenge projects will play a significant role in determining their ultimate outcomes.

\section{Notes}

1. Around 2000 and during the first decade of the twentyfirst century, a number of other documents appeared defining or listing so-called Grand Challenges in various fields; some could be seen as academic Grand Challenge papers, others as appeals for allocation of R\&D endeavors and the necessary funding. For example, in 1998 Sears publishes 'Grand Challenges in Computational Biology' (in Salsberg, Seals and Kasif (eds) Computational Methods in Molecular Biology, Elsevier, 1998); global health scientists, under the leadership of Dr Abdallah
Daar, identified a set of Grand Challenges in Chronic Noncommunicable Diseases (published in Nature magazine in November 2007); US National Academy of Engineering published Grand Challenges in Engineering in 2008, a work also mentioning reverse engineering of the brain; or the 2010 commitment to use science, technology, and innovation to address Grand Challenges by Dr Rajiv Shah (the Administrator of US Agency for International Development), etc. Omenn (2006) in his Science article also gives a short overview of some Grand Challenge endeavors, for example, inside scientific and engineering fields; he, however, does not focus on brain research Grand Challenges.

2. We can emphasize two milestones. First, the naming of one of the pillars of the EU's main research and innovation program Horizon 2020 as Societal Challenges. These are closely related to Grand Challenges and have emerged from discussions on the need for Europe's research system to respond to a series of Grand Challenges (see e.g. the opinion by the then chair of the EC's ERA Rationales Expert Group, Georghiou (2008)). Second, the US Presidents 21st Century Grand Challenges-Obama's Grand Challenge manifesto declares a series of Grand Challenges.

3. DALY is a unit for measuring the amount of health lost because of a disease or injury and is calculated as the present value of disability-free life that is lost as a result of the premature deaths or disability.

4. Markram has been an important figure even before the beginning of the Blue Brain Project. In 2002, he founded the Brain Mind Institute at the EPFL, the leading partner of the HBP. The Blue Brain Project started with EPFL and IBM signing an agreement in 2005 (note that IBM never funded the project per se). In January 2007, it was presented to the Davos forum and in 2013-the same time HBP became a flagship initiative-the Blue Brain Project becomes a National Research Infrastructure. Interestingly, Blue Brain was sometimes heavily criticized as scientists have even claimed that the Blue Brain 'as a scientific folly and a waste of public money ... would sap support from other areas of brain research' (Enserink and Kupferschmidt 2014).

5. They can be found at: http://www.whitehouse.gov/adminis tration/eop/nec/StrategyforAmericanInnovation; https://www. whitehouse.gov/innovation/strategy; and https://www.white house.gov/sites/default/files/strategy_for_american_innovati on_october_2015.pdf.

6. Indeed just prior to ending the first Ramp-Up phase at the end of April and entering the Operational phase the HBP has offered initial versions of six ICT Platforms to users outside the Project, consisting of prototype hardware, software tools, databases, and programming interfaces (some freely accessible, others available after a successful peerreviewed application). Some scientist warn that we are yet to see, how these will resonate with brain researchers 
outside the project (Schiermeier and Abbott 2016).

7. As already written, the selection of the flagships has been a multiyear and a multistep procedure. Of twenty-one eligible proposals received following the initial call, six pilots ('preparatory actions') were selected in January 2011, after which six contenders received around $€ 1.5$ million in funding over a year to refine their proposals. At the end of October 2012, six finalists submitted their complete research proposals, including a roadmap and implementation plan, together with a detailed and thorough justification for the proposed investment. Only two were selected in the end.

8. These can be found at: http://www.flagera.eu/wp-content/ uploads/2016/02/FLAG-ERA-JTC2015-Call-Announcement.

pdf; and http://www.flagera.eu/wp-content/uploads/2016/ 02/FLAG-ERA-JTC2016-Call-Announcement.pdf.

9. The commitment of the Simons foundation in 2014 represents-beside the Allen Foundation support-the biggest (nongovernmental) contribution to date and the involvement of one of the biggest US foundations, as well as a somewhat older foundation incorporated during the Decade of the Brain. Interestingly, Kavli's promised $\$ 4$ million per year for the next 10 years, is basically the amount of their distributed grants in its entirety and will in total drain the foundation of more than a fourth of its total assets (comparing this with the data found in Foundation Directory Online-signaling also a strong financial commitment to this project. Nonetheless, it remains in financial sense among the smaller private contributors.

10. Same could be said for other policy initiatives (see e.g. Anadon's 2012 analyses of energy R\&D in three countries).

\section{References}

Alivisatos, A. P., Chun, M., Church, G. M., et al. (2012) 'The Brain Activity Map Project and the Challenge of Functional Connectomics', Neuron, 74: 970-4.

Brooks, H. (1978) 'The Problem of Research Priorities', Daedalus, 107: 171-90.

Castillo, S. (2015) 'Brain Awareness Week 2015: How Brain Research Has Progressed, and Ways You Can Enhance Cognition', Medical Daily (14 Mar. 2015) <http://www.medicaldaily.com/brain-awareness-week-2015how-brain-research-has-progressed-and-ways-you-can-enhance-325732> accessed 15 May 2016.

Collins, P. Y., Patel, V., Joestl, S. S., and March, S. D., et al. (2011) 'Grand Challenges in Global Mental Health', Nature, 475: 27-30.

Cook Deegan, R. (1994) The Gene Wars: Science, Politics, and the Human Genome. New York: W.W. Norton \& Company.

Dernis, H., Squicciarini, M., and de Pinho, R. (2015) 'Detecting the Emergence of Technologies and the Evolution and Co-development Trajectories in Science (DETECTS): A 'Burst' Analysis-Based Approach', The Journal of Technology Transfer, 41: 930-960.

de Sola Price, D. (1984) 'The Science/Technology Relationship; the Craft' of Experimental Science, and Policy for the Improvement of High Technology Innovation', Research Policy, 13: 3-20.

Dickson, D. (1988) The New Politics of Science. Chicago: Chicago Press.

DiLuca, M., and Olesen, J. (2014) 'The Cost of Brain Diseases: a Burden or a Challenge?', Neuron, 82: 1205-8.
Dosi, G., Llerena, P., and Sylos Labini, M. (2005) 'Science-technology-industry links and the "European paradox": Some notes on the dynamics of scientific and technological research in Europe' <http://www.lem.sssup.it/ WPLem/2005-02.html> accessed 20 Aug 2015.

Elsevier (2014) 'Brain Science: Mapping the Landscape of Brain and Neuroscience Research from 2014' < https://www.elsevier.com/_data/ assets/pdf_file/0004/53455/ElsevierBrainScienceReport2014-web.pdf > accessed 10 Apr 2016.

Enserink, M., and Kupferschmidt, K. (2014) 'Updated: European Neuroscientists Revolt Against the E.U.'s Human Brain Project', Science (11 Jul. 2014) <http://news.sciencemag.org/brain-behavior/2014/07/updatedeuropean-neuroscientists-revolt-against-e-u-s-human-brain-project $>\quad$ accessed 15 Mar 2015.

European Commission (2011) 'European Forward-Looking Activities: Building the Future of 'Innovation Union' and ERA' < https://ec.europa.eu/ research/social-sciences/pdf/policy_reviews/european-forward-lookingactivities_en.pdf $>$ accessed 10 Jul 2015.

_ (2013) 'Graphene and Human Brain Project Win Largest Research Excellence Award in History, as Battle for Sustained Science Funding Continues' <http://europa.eu/rapid/press-release_IP-13-54_en.htm> accessed 10 Jul 2015.

— (2014) 'HORIZON 2020, Work Programme 2014 - 2015: 2. Future and Emerging Technologies Revised' <http://ec.europa.eu/research/partici pants/data/ref/h2020/wp/2014_2015/main/h2020-wp1415-fet_en.pdf > accessed 10 Jul 2015.

Fields, D. R. (2013) 'Neuroscience: Map the Other Brain. Comment', Nature (4 Sep. 2013).

Finger, S. (1994) Origins of Neuroscience: A History of Explorations in Brain Function. New York: Oxford University Press.

Fitzpatrick, S. (2016) 'The Lore of Biomedical Science Policy; the Case of Brain Science'. Essay for the CSPO Workshop: The Politics of Science and Innovation Policy, Brookings Institution, 16-17 March $2016<$ http://cspo. $\mathrm{org} /$ research/workshop-the-politics-of science-and-innovation-policy/> accessed 20 Mar 2016.

Flyvberg, B., Bruzelius, N., and Rothengatter, W. (2003) Megaprojects and Risk: An Anatomy of Ambition. Cambridge: Cambridge University Press.

Foray, D., Mowery, D. C., and Nelson, R. R. (2012) 'Public R\&D and social challenges: What lessons from mission R\&D programs?', Research Policy, 41: 1697-1702.

Georghiou, L. (2008) 'Europe’s Research System Must Change', Nature, 452: 935-6.

Grand Challenges Canada (2011) 'The Grand Challenges Approach' < http:// www.grandchallenges.ca/wp-content/uploads/2011/02/thegrandchallenge sapproach.pdf/> accessed 10 Jul 2015.

Hicks, D. (2016) 'Grand Challenges in US Science Policy Attempt Policy Innovation', Journal of Foresight, 11: 22-42.

Holzinger, A., (2014) Biomedical Informatics: Discovering Knowledge in Big Data. Heilderberg/New York: Springer.

Horgan, J. (2013) 'Do Big, New Brain Projects Make Sense When We Don't Even Know the "Neural Code"', Scientific American (23 Mar. 2013) <http://blogs.scientificamerican.com/cross-check/2013/03/23/do-big-newbrain-projects-make-sense-when-we-dont-even-know-the-neural-code/> accessed 10 Jul 2015.

Insel, T. R., Landis, S. S., and Collins, F. S. (2013) 'The NIH BRAIN Initiative', Science, 340: 687-8.

Irvine, J., and Martin, B. R. (1985) 'Evaluating Big Science: Cern's Past Performance And Future Prospects', Scientometrics, 7: 281-308.

ISTAG (2009a) 'Recommendations on Future and Emerging Technologies', $<$ http://cordis.europa.eu/fp7/ict/fet-proactive/docs/press-23-fet-istag2009_ en.pdf $>$ accessed 20 Aug 2015.

— (2009b) 'Report on European Challenges and Flagships 2020 and beyond', $<$ http://cordis.europa.eu/pub/ist/docs/istag/flag-fet-july09_en.pdf > accessed 20 Aug 2015.

JIIP (2012) 'Study to assist the European Research Area Board: Investing in Research and Innovation for Grand Challenges' < https://ec.europa.eu/ research/erab/pdf/erab-study-grand-challanages-2012_en.pdf/> accessed 20 Aug 2015. 
Jones, E. G., and Mendell, L. M. (1999) 'Assessing the Decade of the Brain', Science, 284: 739.

Kaiser, J., Marshall, E., and Zahn, L. (2010) 'An Interview with Francis Collins at the NIH', Science, 328: 1090-1.

Kalil, T. (2012) 'The Grand Challenges of the 21st Century: Prepared Remarks at the Information Technology and Innovation Foundation', 12 April 2012, Washington, DC < https://www.whitehouse.gov/sites/default/files/microsites/ ostp/grandchallenges-speech-04122012-rev.pdf > accessed 5 Jun 2016.

Kallerud, E., Klitkou, A., Sutherland Olsen, D., et al. (2013) 'Dimensions of Research and Innovation Policies to Address Grand and Global Challenges: Position Paper of the CPRI Project' < http://www.euspri-forum.eu/key_mis sions/CPRI_Position_paper.pdf/> accessed 15 Jul 2015.

Kandel, E. R., and Squire, L. R. (2000) 'Neuroscience: Breaking Down Scientific Barriers to the Study of Brain and Mind', Science, 290: 1113-20.

Kleinberg, J. (2003) 'Bursty and Hierarchical Structure in Streams', Data Mining and Knowledge Discovery, 7: 373-97.

Koch, C., and Reid, R. C. (2012) 'Neuroscience: Observatories of the Mind', Nature, 483: 397-8.

Kuhlmann, S., and Rip, A. (2014) 'The Challenge of Addressing Grand Challenges. A Think Piece on How Innovation Can Be Driven Towards the "Grand Challenges" as Defined under the European Union Framework Programme Horizon 2020', Report to ERIAB < https://ec.europa.eu/re search/innovation-union/pdf/expert-groups/The_challenge_of_addressing_ Grand_Challenges.pdf $>$ accessed 5 Dec 2015.

Levidow, L., and Papaioannou, T. (2016) 'Policy-Driven, Narrative-Based Evidence Gathering: UK Priorities for Decarbonisation Through Biomass', Science and Public Policy, 43: 46-61.

Link, A. N. (2014) 'Introduction to Special Section: A Retrospective Look at US Science and Technology Policy', Science and Public Policy, 41: 409-10.

Mowery, D. C. (2012) 'Defense-Related R\&D as a Model for "Grand Challenges" Technology Policies', Research Policy, 41: 1703-15.

OECD (2015) OECD Science, Technology and Industry Scoreboard 2015: Innovation for Growth and Society. Paris: OECD Publishing.

Olesen, J., Baker, M. G., Freund, T., et al. (2006) 'Consensus Document on European Brain Research', Journal of Neurology, Neurosurgery and Psychiatry, 77: 1-44.

Omenn, G. S. (2006) 'Grand Challenges and Great Opportunities in Science,

Technology, and Public Policy', Science, 314: 1696-704.

Open Letter (2014) 'Open Letter' <http://www.neurofuture.eu/> accessed 10 Dec 2015 .
Pechura, C. M., and Martin, J. B. (1991) Mapping the Brain and Its Functions: Integrating Enabling Technologies into Neuroscience Research. Washington, DC: National Academy Press.

Reardon, S. (2014) 'Brain-mapping Projects to Join Forces', Nature (18 Mar. 2014) <http://www.nature.com/news/brain-mapping-projects-to-join-forces$1.14871>$ accessed $10 \mathrm{Jul} 2015$.

Sampat, B. N. (2012) 'Mission-oriented Biomedical Research at the NIH', Research Policy, 41: 1729-41.

Saxena, S., Thornicroft, G., Knapp, M., et al. (2007) 'Resources for Mental Health: Scarcity, Inequity, and Inefficiency', The Lancet, 370: 878-89.

Schiermeier, Q., and Abbott, A. (2016) 'Flagship Brain Project Releases Neuro-computing Tools', Nature (31 Mar.) <http://www.nature.com/ news/flagship-brain-project-releases-neuro-computing-tools-1.19672> accessed 5 Apr 2016.

Shreeve, J. (2004) The Genome War: How Craig Venter Tried to Capture the Code of Life and Save the World. New York: Alfred A. Knopf.

Singer, P. A., Books, D., and Daar, A. S. (2011). The Grand Challenges Approach. Toronto: Grand Challenges Canada/Grand Défis Canada.

Sobocki, P., Lekander, I., Berwick, S., et al. (2006) 'Resource Allocation to Brain Research in Europe (RABRE)', European Journal of Neuroscience, 24: 2691-3

The White House (2016) 'Obama Administration Proposes Over \$434 Million in Funding for the BRAIN Initiative' < https://www.whitehouse. gov/sites/whitehouse.gov/files/documents/BRAIN\%20Initiative \%20FY17 $\% 20$ Fact \%20Sheet.pdf $>$ accessed 10 Apr 2016.

Veugelers, R., and Cincera, M. (2015) 'How to Turn on the Innovation Growth Machine in Europe', Intereconomics, 1: 4-9.

Wade, N. (2010) 'Early History: From Galen to Golgi'. In: C., Schoonover (ed.) Portraits of the Mind: Visualizing the Brain from Antiquity to the 21st Century. New York: Abrams.

WHO (2008) 'The Global Burden of Disease'. <http://www.who.int/health info/global_burden_disease/GBD_report_2004update_full.pdf $>$ accessed 20 Aug 2015.

Wissenshaftsrat (2015) 'Grand Societal Challenges as a Topic for Science Policy'. Position Paper Drs. 4594-15, 1-32. < http://www.wissenschaftsrat. de/download/archiv/4594-15_engl.pdf $>$ accessed 5 Jun 2016.

Yuste, R., and Church, G. M. (2014) 'The New Century of the Brain', Scientific American, 310: 38-45.

Zimmer, C. (2004) 'A Distant Memory of the Brain', Science, 303: $43-4$. 